\title{
PEDAGOGIA COMO TRANSFERÊNCIA CULTURAL NO ESPAÇO FRANCO-SUÍÇO: MEDIADORES E REINTERPRETAÇÕES DE CONHECIMENTO (1850-1900)
}

\author{
Alexandre Fontaine \\ Universidade de Genebra, Suíça.
}

Resumo

Neste artigo pretende-se reavaliar a circulação dos conhecimentos pedagógicos no espaço franco-suíço. Metodologicamente propomos dar ênfase nas modalidades de passagem desses conhecimentos de um contexto cultural a outro, estudando os atores, os intermediários, bem como as inevitáveis transformações semânticas que, necessariamente, acompanham estes intercâmbios transnacionais. Salienta-se como os conhecimentos pedagógicos europeus, elaborados de maneira coletiva, são declinados diversamente segundo as especificidades locais. Neste sentido, trata-se de demonstrar que, ao se concretizarem as identidades, as especificidades nacionais são cada vez mais exaltadas por ocasião de exposições universais e os exotismos logo desvalorizados, até mesmo dissimulados em proveito de certo talento nacional. Neste texto procura-se contextualizar esta aparência enganosa de Sonderfälle, para pôr em evidência, de maneira vantajosa, a construção coletiva de uma pedagogia europeia mesclada.

Palavras-chave: transferências culturais, transformação semântica, circulação dos conhecimentos, história da pedagogia europeia, Ferdinand Buisson, Terceira República.

\section{PEDAGOGY AS CULTURAL TRANSFER: BROKERS AND REINTERPRETATIONS OF KNOWLEDGE BETWEEN SWITZERLAND AND FRANCE (1850-1900)}

\begin{abstract}
This paper seeks to reassess the way in which pedagogical knowledge circulated between France and Switzerland. In terms of method, we have chosen to focus on the way in which this knowledge passed from one cultural context to another by studying the related actors and vectors, as well as the inevitable semantic transformations which, of necessity, accompany transnational exchanges of this nature. The paper also highlights the way in which European pedagogical knowledge, developed collectively, was applied in a variety of ways depending on local particularities. The issue here is to show the way in which, as identities became more firmly established, distinctive national features were increasingly honoured at Universal Expositions, while the various forms of exoticism soon fell out of favour, sometimes even to the point of being concealed in favour of national genius. This paper therefore seeks to contextualise the deceptive semblance of
\end{abstract}


Sonderfälle and provide a clearer picture of the collective emergence of a multifaceted European pedagogy.

Key-words: cultural transfer, semantic transformation, circulation of knowledge, history of european pedagogy, Ferdinand Buisson, French Third Republic.

\section{PEDAGOGÍA COMO TRANSFERENCIA CULTURAL EN EL ESPACIO FRANCO-SUIZA: MEDIADORES Y REINTERPRETACIONES DE CONOCIMIENTOS (1850-1900).}

\section{Resumen}

Este artículo tiene la intención de volver a evaluar la circulación del saber pedagógico en el entorno franco-suizo. Metodológicamente, se propone centrarse en cómo transmitir este conocimiento de un contexto cultural a otro, el estudio de los agentes, intermediarios, así como las transformaciones semánticas inevitables que necesariamente acompañan a estos intercambios transnacionales. Este artículo permite enfatizar cómo los conocimientos pedagógicos europeos, elaborados colectivamente, son reduzidos de diferente manera, de acuerdo a las especificidades locales. En este sentido, se demuestra que, al materializar las identidades, sus peculiaridades nacionales son cada vez más exaltadas con motivo de las exposiciones universales y los representaciones exóticas devaluados y disimuladas en favor de algún talento nacional. Este artículo pretende contextualizar esta apariencia engañosa de Sonderfälle, para destacar, de forma ventajosa, la construcción colectiva de una pedagogía europea mezclada.

Palabras-clave: transferencias culturales, procesamiento semántico, la circulación del conocimiento, la historia de la pedagogía europea Ferdinand Buisson, Tercera República.

\section{LA PÉDAGOGIE COMME TRANSFERT CULTUREL DANS L'ESPACE FRANCO-SUISSE: MÉDIATEURS ET RÉINTERPRÉTATIONS DE SAVOIRS (1850-1900).}

\section{Résumé}

Cet article vise à réévaluer la circulation des savoirs pédagogiques dans l'espace franco-suisse. Méthodologiquement, nous nous proposons d'insister sur les modalités de passage de ces savoirs d'un contexte culturel à l'autre, en étudiant les acteurs, les vecteurs, ainsi que les inévitables transformations sémantiques qui accompagnent nécessairement ces échanges transnationaux.

Cet article permet de souligner comment les savoirs pédagogiques européens, élaborés de manière collective, sont diversement déclinés selon des spécificités locales. Dans ce sens, il s'agit de montrer qu'à mesure que les identités se solidifient, les spécificités nationales sont de plus en plus exaltées lors des Expositions universelles et les exotismes bientôt dévalorisés, voire même dissimulés au profit d'un certain génie national. Cet article souhaite donc contextualiser cette apparence trompeuse de Sonderfälle, pour mettre davantage de relief dans la construction collective d'une pédagogie européenne métissée.

Mots-clé: transferts culturels, transformation sémantique, circulation des savoirs, histoire de la pédagogie européenne, Ferdinand Buisson, Troisième République. 


\section{Introdução: as transferências culturais ou Kulturtransferforschung ${ }^{1}$}

$\mathrm{N}$ a obra cujo título evocativo é Faut-il penser autrement l'histoire du monde?, Christian Grataloup indica os diferentes níveis de compreensão da narração mundial:

Quanto mais o mundo existir, tanto mais a consciência coletiva necessita de um relato de acordo com este nível, uma história comum do porvir da humanidade. Entretanto, se não assumir um angelismo total, a História Mundial só poderá ser declinada a partir das suas encarnações locais. (2011, p. 38)

Nesta perspectiva, estudar as relações pedagógicas franco-romandas ${ }^{2}$ do século 19 torna-se instrutivo, no sentido em que esta abordagem permite analisar as modalidades de circulações de conhecimentos e de práticas escolares por uma relação assimétrica entre uma região e uma nação. Este procedimento parece tanto mais eficiente quando estivermos cientes de que diversas figuras centrais da proscrição francesa de 2 de dezembro de 1851 - Edgar Quinet e Ferdinand Buisson, chefiando - instalaram-se durante diversos anos na Suíça antes de contribuir para a estruturação da escola republicana francesa.

Ademais, Buisson não esconderá os diversos intercâmbios operados entre a Suíça e a França, constatando, em 1916, que "a nossa escola primária sob a Terceira República se inspirou fortemente na sua" (p. 22). Além disso, quando se percorre o Mémorial d'exil de Hermione Quinet ou o Journal de responsabilidade de Jean-Aristide Claris (1872), ficamos impressionados com a aura que o país acolhedor exerceu sobre os proscritos. Quinet escrutou, comparou, ao passo que Buisson se colocou na condição de estudante da democracia helvética. A sua maleta continha, especialmente, ferramentas susceptíveis de reerguer a França após os traumatismos ocorridos entre 1870 e 1871.

O refúgio helvético certamente incentivou à reflexão. Quando os irreconciliáveis convocaram um congresso de paz e de liberdade em Genebra, em 1867, com a finalidade de lançar as bases dos Estados Unidos da Europa, não restou a menor dúvida para Jules Barni $^{3}$ que o exemplo da Suíça confederativa oferecia a estrutura ideal do sistema a ser adotado:

Nossa ideia se apoia, aliás, em uma realidade viva que pode servir ao mesmo tempo de modelo e de núcleo central à organização da Europa. Refiro-me à Suíça, onde nossa liga, por este motivo mesmo, estabeleceu a sua sede. A Suíça não compreende vinte e dois Estados independentes que pertencem a nacionalidades e idiomas diferentes? $\mathrm{E}$ esses vinte e dois Estados não formam uma Confederação que, deixando a cada um a sua autonomia, os une para a regulamentação e a defesa dos seus interesses comuns, mantendo entre eles a harmonia e a paz? Trata-se realmente do sistema que se pretende estender em toda a Europa. O que a Suíça é em tamanho pequeno, é preciso que a Europa se torne em tamanho grande,

\footnotetext{
${ }^{1}$ Este artigo é uma publicação parcial e adaptada do capítulo 7 da tese de Fontaine 2013. Ademais, ele será publicado em francês na obra coletiva Hofstetter \& Droux.

${ }^{2}$ A Suíça romanda é a Suíça francófona.

3 Jules Barni (1818-1878), propagador de Kant na França, dirigia a cadeira de história na Universidade de Genebra desde 1861, recomendado por Quinet. 
se ela quiser extirpar para sempre do seu seio o flagelo da guerra e dos exércitos permanentes. (Barni, 1869, p. 9)

$E$ se as nossas estruturas escolares nacionais não fossem de fato senão a realização de absorções e de apropriações recíprocas? E se para parafrasear Thiesse (1999), não houvesse nada de mais internacional do que a formação dos sistemas escolares nacionais? Esta é a nossa hipótese. Este artigo terá, portanto, como objetivo considerar estes intercâmbios franco-romandos pelo prisma da Kulturtransferforschung, para considerar os fenômenos de reinterpretações e mostrar o papel decisivo da pluralidade de atores na aculturação de conhecimentos entre a Suíça e a França.

Werner (2006) define a abordagem das transferências culturais nos seguintes termos:

Os estudos de transferência pretendem analisar as interações entre culturas e sociedades - ou frações e grupos pertencentes a uma sociedade - na sua dinâmica histórica, justificando as condições que marcaram o seu desencadeamento e o seu desenvolvimento, examinando os fenômenos de emissão, de divulgação, de recepção e de reinterpretação que os constituem, enfim esmiuçando os mecanismos simbólicos por meio dos quais se recompõem os grupos sociais e as estruturas que os sustentam. (p. 1190)

O principal interesse desta escola metodológica se encontra no posicionamento dinâmico segundo o qual os pais da Kulturtransferforschung consideram as circulações. Assim, o estudo das transferências se propõe a iniciar a partir dos movimentos e circulações empíricas entre culturas e sociedades (Werner, 2006, p. 1190). Por isso, para Grataloup (2011, p. 38), trata-se bem menos de colecionar lado a lado uma série de descrições e relatos do que articulá-los uns aos outros. Mombert (2001, p. 12) salienta que este procedimento metodológico convida a "não comparar dados estatísticos, mas a procurar captar dinâmicas", seguindo concretamente a trajetória das transferências por meio de uma análise tríplice: seleção - transmissão - reinterpretação.

Este modo operante próprio à Kulturtransferforschung nos parece particularmente adaptado para analisar os três tempos de cada transferência. Trata-se, inicialmente, de se interrogar sobre as motivações, os interesses que levam o contexto cultural de recepção a desejar importar um conhecimento modelado em outro contexto. Em um segundo tempo, questionaremos sobre o processo de mediação, sobre estes atores individuais que, por diversas razões, se encarnam em líderes e permitem a transferência do saber cobiçado. Finalmente, estudaremos a transformação semântica que acompanha, obrigatoriamente, a transferência quando da passagem de um contexto cultural a outro. As múltiplas declinações do ensino mútuo ilustram perfeitamente este fenômeno de ressemantização.

Nascido em um contexto especial em Madras, este método sofreu uma primeira transformação quando foi aculturado na Inglaterra por Bell e Lancaster. Os filantropos franceses, que o estudaram in loco, o transformaram por ocasião da sua passagem para o continente. O mutualismo teve novas modificações substanciais quando o Père Girard o impôs nas suas escolas em Friburgo. Desde então os patriotas italianos vieram experimentar o sistema às margens do Sarine e declinaram uma nova versão. Este método devia, para estes patriotas do Risorgimento, facilitar a divulgação em grande 
escala de uma propaganda nacional liberal, incluindo os territórios há muito tempo submetidos à ocupação estrangeira.

Assim, quatro estudos de caso para esclarecer os mecanismos de importação de conhecimentos específicos entre a Suíça e a França, constituirão o centro empírico da presente contribuição, começando pela aculturação laicizada de uma obra de instrução cívica utilizada no cantão de Friburgo desde 1856.

\section{O manual suíço do cidadão francês}

Quando da passagem pelos recônditos suíços os proscritos de 2 de dezembro de 1851 permaneceram, por razões evidentes, particularmente atentos ao ensino da instrução cívica, bem como à diversificação dos manuais adotados. Os cantões romandos dispunham, de fato, de uma oferta abundante: as obras eram renovadas a cada mudança cantonal. Tratava-se de preparar, não sem resistências, a conversão dos franceses para o seu papel de cidadão republicano e garantir a unidade espiritual da nação. Não foi por acaso que Buisson, prazerosamente, salientou na conferência proferida em Neuchâtel em 1916, que

saber ler, escrever e contar não basta, todos estão de acordo, mas o que é necessário acrescentar? Inicialmente, sem dúvida, elementos de instrução cívica, pois o povo só é soberano se o cidadão for esclarecido. Há muito tempo, a Suíça agia com precaução, e essa foi a primeira importação que dela fizemos. (1916, p. 24)

\section{Duas declinações do Curso de Louis Bornet}

Pouco antes do retorno dos conservadores e da supressão do ensino cívico em Friburgo, o gruyérien Louis Bornet (1818-1880) publicou, em 1856, a obra Cours gradué d'instruction civique (para a escola, a família e o cidadão), logo declinado pelos cantões protestantes romandos e, mais tarde, remanejado pelas necessidades da recente escola da Terceira República.

É interessante constatar que a obra de Bornet, criada originalmente no espírito de Girard para as escolas do cantão católico de Friburgo, sofreu um número considerável de modificações para ser apropriada ${ }^{4}$ às escolas do cantão de Neuchâtel, em 1864, e mais tarde às do cantão de Vaud, em 1872, todas as duas reformuladas ${ }^{5}$. Os bons manuais desfrutam, então, de uma difusão entre os cantões. Isso garantiu, a termo, certa padronização dos meios de ensino romandos.

Deve-se a ideia de uma reformulação laicizada do Cours de Bornet a Quinet, estabelecido nos arredores de Montreux desde 1858. Quanto a isso, é importante sublinhar a ascendência da experiência escolar suíça sobre as ideias educativas de Quinet, que se colocava continuamente como espectador atento:

Nesta Suíça republicana onde nós encontramos por tanto tempo um refúgio, admirei seguidamente no povoado, os pequenos resumos que a criança levava da escola, pois eles formavam um Manual do Cidadão Suíço. As tradições que tornam o homem livre já eram objeto dos ditados

\footnotetext{
${ }^{4}$ Segundo a terminologia adotada por Daguet, ver L'Éducateur, 3/1872, p. 40.

5 Para uma análise das principais modificações entre as diferentes versões de 1856, 1865 e 1872 , ver Bovet, 1932, p. 216-218. 
destes cidadãos de dez a doze anos. Elas se inculcavam por si só nestas mentes em formação. Misturadas às primeiras impressões rústicas do pequeno camponês, escritas na página ainda branca do livro da vida, nada poderia apagá-las! Por que, eu me perguntava, nós não veríamos algo de semelhante na França? A verdadeira noção de liberdade não perde, tão facilmente, as raízes em nós somente porque ela é semeada demasiadamente tarde, na superfície, nas inteligências, e, unicamente pelas tempestades. Façamos que ela se mescle às nossas primeiras noções: ela será para nós uma das raízes da existência, enterremos a boa semente mais profundamente: os ventos não a levarão mais. (1872, p. $\mathrm{XVI})$

Para Quinet o renascimento da França devia, obrigatoriamente, passar pela introdução de um curso de ensino cívico. Ele também encarregou outro proscrito, o alsaciano Georges Joseph Schmitt (1813-1875), para fornecer um Manuel du citoyen français para a França, com bases no manual de Bernet.

Schmitt iniciou a sua carreira como professor em Mulhouse. Intelectualmente sabemos que ele se interessava pelas teses dos falansterianos, bem como por Proudhon, que ele descobriu em 1845. Correspondente de Cabet, leu Considerant e Owen. No momento do golpe de Estado de 2 de dezembro de 1851, se dedicava à redação do semanário Die Volksrepublik, em Colmar. Condenado à expulsão do território francês, atravessou a fronteira e chegou, no dia 10 de dezembro, na Basileia, antes de dirigir-se à capital helvética. Protegido pelo conselheiro federal radical Druey, Schmitt residiu um determinado tempo em Aarau, em condições particularmente difíceis para ele e a sua família (Vuilleumier, 1974). Igualmente, após uma primeira recusa e na necessidade de encontrar um emprego, aceitou a redação do jornal de Friburgo Le Confédéré. Não podemos, então, ignorar que foi a partir de um dos bastiões católicos da Suíça que se organizou a resistência republicana: "O ideal do jornalista republicano ainda existia em algum lugar em 1869 [...]. Ele vivia no exílio. Onde? No centro do núcleo da reação católica, clerical, em Friburgo. O redator-chefe do Confédéré escrevia sozinho esse excelente jornal (verdadeiro monitor da proscrição)", relatou Hermione Quinet nas suas Mémoires d'exil (1870, p. 255).

No momento de trabalhar no Cours de Bornet, Schmitt não era iniciante em matéria de obra pedagógica. Ele já tinha editado um pequeno livro intitulado Utopie, no qual formulou um projeto de lei sobre a instrução pública elementar. Do Cours de Bornet de 1856 ao Manuel du citoyen français de 1872, notaremos que a principal ressemantização é de ordem dogmática e confessional. No prefácio Schmitt indicou ter "evitado, cuidadosamente, de tratar, mesmo através de alusão distante, questões dogmáticas e confessionais" (1872, p. VIII). Consequentemente, o alsaciano afastou sistematicamente as formulações religiosas presentes em Bornet - Père Girard, Providência, Deus, Igreja, Religião, Paróquia, Jesus, etc. Em compensação, a graduação prezada por Girard e a divisão em quatro cursos adotada por Bornet são conservadas.

Além do manual tratava-se, também, de demonstrar o fundamento do ensino cívico após o traumatismo de 1870. Podemos dizer, sob este ponto de vista, que a experiência estrangeira, e, principalmente a da Suíça, foi utilizada por Schmitt para legitimar e apressar o movimento na França: "Este ensino é dado nos Estados livres. Na Suíça, o ensino cívico é matéria obrigatória em todas as escolas, e o nosso manual, adaptado às instituições locais, é utilizado em diversos cantões". Schmitt acrescenta que "na Alemanha 
o grande Diesterweg solicitou este ensino desde 1833"; assim, na França, "a questão chegou, portanto, à maturidade. É necessário concretizar a ideia, aplicando-a simultaneamente a nível superior e inferior, especialmente inferior" (1872, p. XII-XIII).

É justamente nesta mesma perspectiva de iniciação à República para o povo que Gambetta, que chegou de dirigível em Tours em 9 de outubro de 1870, encarregou o filósofo Barni para elaborar a redação do Bulletin de la République ${ }^{6}$. Este jornal de propaganda, segundo Barni, "era destinado a esclarecer as populações do interior, como das cidades, não somente sobre os atos do governo da defesa nacional, mas também sobre as instituições republicanas, as únicas que podiam reerguer a França" (1872, p. V). Em outros termos, tratava-se "de inserir, em cada número, com o título Manuel républicain, um capítulo curto onde me esforçava em colocar ao alcance de todas as inteligências as noções fundamentais que constituem o próprio espírito da república" (ibid.). Com Barni, chamado do seu exílio em Genebra assim que foi proclamado o Governo da Defesa Nacional, Gambetta dispunha de um intelectual-chave que estudou as instituições helvéticas com assiduidade e interesse, como atestam as múltiplas referências à Suíça presentes no seu Manuel. Convencido do papel da educação e da moral laica como único meio de chegar ao self-government, Barni privilegiou a constituição de hábitos republicanos a fim de garantir a perenidade das instituições.

Devemos, entretanto, ressaltar que se os manuais de Schmitt e Barni tiveram uma divulgação fraca, pelo menos atraíram a atenção da elite sobre a necessidade de um ensinamento cívico e forneceram um modelo suíço, servindo de base para as obras de $1882^{8}$.

A renovação patriótica das nações passou também pelo culto do corpo. Desde o turnvater Friedrich Ludwig Jahn (1778-1852) e o desenvolvimento do turnverein na Alemanha, conhecemos a importância da ginástica e o seu papel para moldar o nacionalismo germânico. Ora, a implantação progressiva de escolas de ginástica nas principais cidades europeias, e no espaço franco-suíço, foi primordialmente o fruto de uma rede de divulgadores muito zelosos.

\section{Ginástica escolar e batalhões militares}

É interessante constatar que, excluindo a Alemanha, a implantação da ginástica escolar na Europa permaneceu essencialmente nas mãos de educadores estrangeiros. Defrance e Joseleau (1991) explicam que esta mobilidade é o resultado da adaptação às leis de um mercado da ginástica no qual se opõem muito cedo empreendedores. Defrance (2001) salienta ainda que para se ocupar de ginástica na primeira metade do século 19' era preciso possuir um espírito de iniciativa, construir a sua posição, obter apoios entre os poderosos, fazer propaganda e demonstrações gratuitas, o que supõe condições materiais. Entre esses, o suíço Phokion Heinrich Clias (1782-1854) figura como um dos organizadores da ginástica nas escolas parisienses da Restauração.

\footnotetext{
${ }^{6}$ Este Bulletin devia substituir o Moniteur des communes que permanecia restrito a Paris.

${ }^{7}$ Assinalamos que o texto de Barni foi, inicialmente, divulgado em episódios no Bulletin de la République.

${ }^{8}$ A instrução cívica foi instituída na França por Jules Ferry (lei de obrigação de 28 de março de 1882). Surge, então, uma profusão de manuais, entre os quais os de Bert (1882), Laloi (1882), Massy (1883). Ver também o estudo dos manuais franceses de Mougniotte (1991); sobre a emergência do objeto de estudo instrução cívica, ler Bensoussan; Laugère (1985).
} 


\section{De Phokion Heinrich Clias a Léon Galley ${ }^{9}$}

Nascido na América do Norte, educado na Holanda, Clias ensinou a sua arte no instituto privado de Gottstatt, perto de Bienne. Oficial de artilharia introduziu, com sucesso, os exercícios corporais entre os soldados. Instalou-se na França no início da Restauração, foi responsável pelo ensino da ginástica nas escolas da cidade de Paris, rivalizando com o coronel espanhol Francesco Amoros (Spivak, 2001). A respeito deste último, Jacques Ullmann salientou que os seus métodos provinham de uma adaptação francesa das ginásticas do turnvater Friedrich Ludwig Jahn (1778-1852) e de Pestalozzi (Bussard, 2007). Este fato se confirma ao sabermos que Amoros utilizou a fundação de um instituto em Madri, criado por Charles IV, que levou da Suíça diversos seguidores de Pestalozzi (Morel-Fatio, 1925).

Em virtude dos seus Éléments de la gymnastique (Aufangsgründe der Gymnastik), uma cópia parcial das teses do saxão GutsMuths, os seus métodos foram institucionalizados na maioria dos cantões suiços e foram conhecidos na Inglaterra. Em 1822 ele obteve o lugar de superintendente-chefe para os exercícios de ginástica do exército inglês. Ferido em 1827, voltou a Ittigen e dirigiu a equitação em Berna de 1833 a 1837. Residindo novamente na Suíça da Regeneração, Clias, competindo com o teólogo Spiess ${ }^{10}$, de Hesse, tentou novamente a sua sorte na França em 1841. Morou em Coppet, em 1849, e ministrou aulas de ginástica para adolescentes em Genebra até a sua morte ${ }^{11}$.

Além disso, a adoção da ginástica escolar foi acompanhada por um "combate pela higiene" (Chanet, 2006, p. 225). A partir do verão de 1871, portanto, bem antes da chegada dos republicanos nos assuntos escolares, uma missão dirigida por Jean-Baptiste Fonssagrives foi enviada para estudar as condições sanitárias nos diferentes estabelecimentos suíços ${ }^{12}$. O resultado se revela sem equívocos:

A organização das escolas para crianças ali é notavelmente avançada e tive diversas vezes um sentimento de lamentar invejosamente, comparando estas escolas espaçosas, bem arejadas, amplamente ensolaradas, possuindo frequentemente um luxuoso mobiliário, ricamente dotadas de todos recursos para o ensino intuitivo, com condições semelhantes às das nossas escolas onde se administra seguidamente o primeiro ensino, tão decisivo, todavia, tanto para a instrução como para a saúde futura ${ }^{13}$.

${ }^{9}$ Esta parte dedicada à ginástica escolar busca inspiração nos trabalhos pioneiros de Véronique Czáka. Ver Éduquer les corps et les âmes: histoire sociale et genrée de l'éducation physique en Suisse romande (19 ${ }^{\mathrm{e}}$ début $20^{\mathrm{e}}$ siècle). Université de Lausanne, tese de doutorado em elaboração.

${ }^{10}$ Adolph Spiess (1810-1858) estudou os métodos do prussiano Jahn, pai da ginástica europeia. O governo decidiu fechar o seu ginásio, julgado muito liberal. A partir disso, Spiess se estabeleceu na Suíça onde divulgou seus preceitos em Berthoud, onde ensinava Fröbel, bem como na Escola Normal de Münchenbuchsee (1835-1843), e, mais tarde, na escola das jovens de Basiléia, antes de se fixar em Darmstadt.

${ }^{11}$ Ver a notícia biográfica de Clias no Journal de Genève, 28 nov. 1854, p. 3.

12 Durante um mês, Fonssagrives visitou as escolas e ginásios de Genebra, Lausana, Neuchâtel, Winterthur, Basileia, Schaffhouse, Zurique, Küsnacht, Wettingen, São Galo, Friburgo, Lucerna, Berna, Burins, Rolle e terminou a sua viagem em Genebra onde ele tinha diversos temas de estudo a completar.

${ }^{13}$ Carta de Jean-Baptiste Fonssagrives ao Ministro Jules Simon, Montpellier, 17 octobre 1871, AN, F1712340.

\begin{tabular}{|c|c|c|c|c|c|}
\hline Hist. Educ. [online] & Porto Alegre & v. 18 & n. 42 & Jan./abr. 2014 & p. 187-207 \\
\hline
\end{tabular}


Fonssagrives, professor de higiene na Universidade de Montpellier, insiste, aliás, sobre as condições específicas atribuídas à ginástica escolar:

Farei o mesmo comentário sobre a maneira realmente inteligente como a pedagogia suíça considera o ensino e as práticas da Ginástica. Nós estamos, no que tange à educação física, em um estado de inferioridade fato que eu desconfiava, mas que não mensurava. Apesar dos esforços louváveis tentados nos últimos anos, a Ginástica educativa não existe no nosso país. Incompleta nos liceus, não existe praticamente em quase todo o ensino primário particular ou público; e podemos afirmar que as meninas estão praticamente excluídas. Visitei os principais Ginásios da Suíça; indaguei aos ginasianos os mais hábeis; assisti às suas aulas; trouxe reproduções fotográficas de ginásios de pequenas cidades, e cheguei à seguinte conclusão: tudo na França, ou quase, restava a ser feito em matéria de ginástica escolar. Não me será difícil demonstrá-lo no trabalho que estou preparando ${ }^{14}$.

$\mathrm{Na}$ França, pela lei de 27 de janeiro de 1880, as aulas de ginástica se tornaram obrigatórias para os meninos, notadamente para a prática regular de exercícios militares elementares (Weber, 1980; Arnaud, 1991, 2000). A respeito disso Jules Ferry publicou o Manuel de gymnastique et des exercices militaires pour les élèves des écoles primaires (1881). Como bem indicou Jean-Claude Bussard (2007), esse manual se inspirou no primeiro manual escolar publicado pela Confederação Suíça em $1876^{15}$. Ambos se caracterizam pela predominância dos valores marciais e dos exercícios militares - dois terços do manual sobre jogos.

Ademais, Czáka (no prelo) mostrou que certos expatriados suíços desempenharam um papel preponderante na promoção da ginástica na França. É o caso de Léon Galley, de Friburgo, que se instalou em Reims (1877-1880), depois em Arras (1880-1887). Durante esses anos, ele publicou uma terminologia de ginástica, exerceu a codireção do primeiro curso de formação para instrutores na França, reformulou os regulamentos referentes às festas de ginástica conforme o modelo suíço e incentivou a participação de sociedades suíças às festas francesas de ginástica.

\section{Imergir os pequenos suíços na Styx}

Após o fracasso de Sedan, assistimos na França a um movimento geral de militarização das consciências, bem como a um apego indefectível à dedicação patriótica. Certamente, a vontade de instruir militarmente o escolar é notória, mas é preciso ver ali, como por muito tempo foi o caso, as raízes de um movimento que deveria culminar com a revanche de 1914? Eugène Paz, diretor do Liceu Condorcet em Paris, assinala em sua obra Gymnastique obligatoire "que é tempo de imergir as nossas crianças na Styx". Além dos discursos, é necessário se questionar sobre os desafios e as finalidades desta intenção. Trata-se de talhar homens para preparar, como desejava Paul Déroulède, para a revanche francesa? Ou o mais importante era de se premunir de qualquer agressão, preparando física e mentalmente uma juventude para a defesa de um território que

\footnotetext{
${ }^{14}$ Carta de Jean-Baptiste Fonssagrives ao Ministro Jules Simon, op. cit.

15 L'École de gymnastique pour l'instruction militaire préparatoire de la jeunesse suisse de l'âge de 10 à 20 ans, Berna: Imprimerie R.-F. Haller-Goldschach, 1876.
} 
queríamos inviolável? Sem pretender entrar no detalhe de causas eminentemente complexas, a transferência dos corpos de cadetes suíços para batalhões franceses traz alguns elementos como resposta.

Albert Bourzac (2004, p. 21) salienta que "o modelo suíço exerceu certa influência na organização dos batalhões escolares", criados por decreto em 1882. Aliás, após uma missão efetuada na Confederação, o oficial de reserva Auguste Frette indicou, em 1879, que "seria desejável que tivéssemos uma organização análoga àquela dos cadetes suíços" (Ibid., p. 19). Além disso, já oito anos antes, em outubro de 1871, Jean-Baptiste Fonssagrives destacava as vantagens desta instituição ao seu ministro Jules Simon:

A introdução da vida militar, do seu espírito e dos seus exercícios nos Ginásios, que correspondem aos nossos Colégios ou Liceus, e mesmo nas divisões superiores do ensino primário, me forneceu um tema de estudos que me interessou consideravelmente. Estudei também detalhadamente a instituição dos Cadetes na Suíça, este celeiro da milícia nacional, e não hesitarei em concluir sobre a necessidade urgente de introduzir nos Colégios esta instituição tão plena de atrativos e de utilidade e que oferece, ao mesmo tempo, tantas garantias ao vigor físico, à pureza e à instrução militar dos jovens. Os exercícios feitos pelas nossas crianças no interior dos liceus não têm nada que possa substituir esta vida ao ar livre, estes exercícios cercados de um verdadeiro aparato militar e estas excursões onde toda a juventude de uma Escola, submetida aos exercícios de fogo de fuzil e mesmo de canhão, parte, com uma música na cabeça, para fazer um reconhecimento estratégico ou simular um ataque. A Saúde, a alegria e os músculos estão bem; a instrução (a experiência está presente para demonstrá-lo) não é prejudicada. Assim se fazem os homens; e, ao mesmo tempo em que são preparados com vigor, física e moralmente, estimula-se fortemente o sentimento nacional, associando-os desde já às ideias de patriotismo e de defesa do país. Os eventos desastrosos pelos quais acabamos de atravessar e a probabilidade de uma mudança completa do nosso sistema militar dariam a esta reforma uma oportunidade muito especial. A opinião a aceitaria neste momento e assim que entrasse nos hábitos, tornar-se-ia uma vantagem incalculável para o país ${ }^{16}$.

Se foi necessário, aproximadamente, uma década para garantir esta transferência de conhecimentos entre a Suíça e a França, convém questionar-se sobre o uso feito no contexto cultural suíço. Mesmo que não seja obrigatoriamente representativo do conjunto dos corpos de cadetes na Suíça romanda, nós optamos, entretanto, por um paralelo com aquele que foi posto em prática por Alexandre Daguet, colega e amigo próximo de Ferdinand Buisson em Neuchâtel entre 1866 e 1870.

\section{Cadetes suíços nos batalhões franceses}

Alguns meses depois da abertura da Escola cantonal de Friburgo, Daguet decidiu-se pela introdução de um corpo militar, com cinco horas de ginástica, sendo três de exercícios militares. Ademais, sabemos que ele desejava assim reatar com a tradição, citando o exemplo do convento de Bellelay, perto de Porrentruy, onde "os exercícios e o uniforme, que era o complemento obrigatório, existia[m] antes da Revolução" (1857, p. 4).

\footnotetext{
${ }^{16}$ Carta de Jean-Baptiste Fonssagrives ao Ministro Jules Simon, op. cit. \begin{tabular}{l|l|l|r|} 
Hist. Educ. [online] & Porto Alegre & v. 18 & n. 42
\end{tabular}

\begin{tabular}{l|l} 
n. 42 & Jan./abr. 2014
\end{tabular} p. $187-207$
} 
Atacado imediatamente a respeito da introdução desses exercícios militares, Daguet (1857, p. 3) defendeu-se invocando a filiação que os unia à antiga Confederação:

Mas os exercícios militares são tão antigos na Suíça quanto a própria Confederação; remontam ao berço das Alianças eternas e datam do tempo da fé religiosa e patriótica, traduzida pela bela divisa: Deus e Pátria [...]. Porém, os exercícios militares não são outra coisa que a consequência e a prática deste princípio fundamental da velha Suíça: "Todo suíço é soldado". Daí a introdução do manejo das armas em quase todos os colégios helvéticos, e a criação destes corpos de cadetes.

Aproveitamos para salientar que os republicanos franceses utilizaram, igualmente, o argumento do fortalecimento e da continuidade histórica no momento da criação dos batalhões escolares. Em 1882 Aristide Rey escrevia para a Revue Pédagogique com o objetivo de vencer as últimas resistências. Tratava-se de mostrar "àqueles que consideram ou consideravam a instituição uma fantasia sedutora", que os batalhões "foram obra dos nossos pais, que nos foram impostos pela nossa tradição nacional, que representam uma instituição indispensável à República" (1882, p. 552).

Não poderíamos deixar de frisar que a prática dos exercícios militares em Friburgo correspondia a uma necessidade de disciplina que se tornou urgente, em uma escola cantonal corroída pela insubordinação. Os cadernos do diretor ${ }^{17}$ mostram os esforços quotidianos feitos pelo conjunto de mestres para corrigir uma juventude pouco dócil: frequência a cabarés, abuso de bebidas alcoólicas, grosserias dirigidas aos passantes, etc. Na pauta do dia 25 de novembro de 1849, descobrimos "que os exercícios militares começarão domingo às 9 horas. Os alunos irão imediatamente após o ofício à praça do liceu para ali se organizarem em pelotões. Todo aluno que não acatar com devido respeito às ordens do chefe será excluído do corpo e não receberá armas" ${ }^{18}$. Na pauta de 17 de junho de 1850 Daguet indicou que "o passeio [a Bulle] será feito militarmente, isto é, com as armas" 19 .

Por esta razão, seria totalmente incorreto considerar Daguet como um militarista engajado. Lembremos que ele foi, a partir de 1867, um dos líderes da contestação romanda contra o projeto Welti, que previa uma cooperação estreita entre a escola e o exército: "Eu também fiz introduzir os exercícios dos cadetes na Escola do cantão, pois eu era reitor em Friburgo em 1848 e presidi as festas dos corpos. Consequentemente, será que eu devia pregar e recomendar o sistema que liga e subordina, de certa maneira, a caserna à Escola?"20 respondeu aos seus detratores em 1874. Daguet esclarece que "não há nada mais contrário à ideia de um educador que aquela de um caporal ou sargento instrutor, incutindo nas crianças, das quais ele deve ser um amigo e um segundo pai, hábitos de disciplina militar". Apelando à "mania pelo militarismo", a adoção desta lei foi, segundo ele, "uma medida funesta à escola, ao seu caráter essencialmente pedagógico, pacífico, intelectual, moral, humanitário" (Châtelain, 1869, p. 115).

17 AEF, Fonds de l'École cantonale, carton 1, livres du directeur (1849-1856). Poderemos constatar as diversas medidas disciplinares tomadas pela Direção do estabelecimento, que levam à introdução dos exercícios militares (cf. os dois primeiros volumes de 1849-1850 e1850-1851).

${ }^{18}$ Ibid.

${ }^{19}$ Ibid.

${ }^{20}$ Journal de Genève, 7 de outubro de 1874, p. 3. 


\title{
Batalhões pacifistas?
}

Se não resta nenhuma dúvida que Buisson compartilhava as ideias pacifistas do seu amigo Daguet, este mantinha também correspondência com Frédéric Passy ${ }^{21}$. Além disso, as suas concepções irenistas eram propagadas na imprensa parisiense, como aqui na Revue Bleue:

\begin{abstract}
Sabemos que existe na Suíça um partido cujo programa é o aumento territorial da Confederação helvética, e que esse partido jamais perdoou à França por não ter cedido às suas reclamações, quando da aquisição da Savoia, alguns distritos da província anexada. Daguet se mostrou contra o que ele chama de patriotismo cosmopolita, um dos inimigos dos mais perigosos do verdadeiro patriotismo, e ele citou, a este respeito, um verso de Lamartine a um oficial suíço que se tornou junto a ele o intérprete dos partidários das conquistas ${ }^{22}$.
\end{abstract}

Do mesmo modo, sem minimizar a ação de Paul Déroulède e da sua Ligue des Patriotes de 1882, é concebível que este espírito vingativo passado, seria nesta mesma perspectiva helvética - física, disciplinar e principalmente cívica - que Paul Bert e os membros da sua comissão da educação militar, instituída em 21 de janeiro de 1822, pensaram na instauração de batalhões. Acusado, como Daguet, na Suíça romanda de querer desenvolver o militarismo, Paul Bert respondeu que

a educação militar me parece o meio mais poderoso, não digo de aumentar, mas de manter o nível moral pelo ensino da obediência racional e dos sacrifícios legítimos. Já dissemos e tornamos a dizer que a nossa tarefa tende a reconduzir ao militarismo, esta espécie de automatismo do corpo e do espírito tão admirado pelos grandes exploradores de homens. Isso representa um erro profundo: a educação militar, ao contrário, é a proteção mais segura contra o militarismo. Ela não desenvolve as tendências servis, mas as qualidades do homem realmente livre já que a liberdade não será mais perturbada nem impedida, mas bem garantida e aclamada pela obediência à regra, à lei ${ }^{23}$. (Bourzac, 2007, p. 93)

Poder-se-ia legitimamente pensar que a transferência dos cadetes suíços para a França pôde se ressemantizar em torno de uma função marcial com objetivos de revanche. Entretanto, a presença de Ferdinand Buisson nesta comissão - ele tinha comparado o uniforme militar com uma vergonhosa entrega e recebeu o prêmio Nobel da Paz em 1927 - deixa supor, como esboça Jean-François Chanet (2006, p. 24-29), que se trata bem da paz e não da revanche que a elite escolar da Terceira República tentou instituir através dos seus programas, apesar de certos comentários muito ambíguos de Buisson (1913):

${ }^{21}$ Frédéric Passy (1822-1912, em dezembro de 1901, dividiu com Henri Dunant o primeiro Prêmio Nobel da Paz. Este pacifista recebeu em 1868 a autorização do governo imperial francês para convocar uma assembléia da Liga Internacional Permanente da Paz que acabava de fundar, em maio de 1867, e, que era, de fato, concorrente da Liga Internacional da Paz e da Liberdade fundada em Genebra (ver Les États-Unis d'Europe. Organe de la Ligue internationale de la paix et de la Liberté, $\mathrm{n}^{\circ} 23,7$ de junho de 1868, p. 1).

${ }^{22}$ Revue politique et littéraire (Revue bleue), Paris, XIV/1878, p. 668.

${ }^{23}$ Alocução de Paul Bert diante da comissão da educação militar (cf. A. Bourzac, 2007, p. 93). Hist. Educ. [online] 
Neste instante, uma palavra diz tudo, parece pelo menos: a "revanche", palavra que não deveria ser julgada com as ideias e os sentimentos que teremos daqui a trinta anos. É preciso se perguntar o que teria sido o moral de um povo no qual não vibrou instantaneamente, no dia seguinte ao desastre, este grito de revolta, este grito de esperança, apesar de tudo, pungente, feroz, brutal. Não seríamos justos em relação aos primeiros discípulos de Fichte como em relação aos primeiros manifestantes da "Liga dos Patriotas" criticando-os sobre a veemência de certos propósitos, o ultraje de certas atitudes. Que mais tarde o nacionalismo tenha ora se corrompido ora explorado com fins políticos, os generosos entusiasmos do primeiro momento, o que importa? No momento, há exasperações que são a sabedoria mesma sob as aparências do delírio. (p. 3)

Se quisermos captar a visão de Buisson a respeito da ideia de revanche, é necessário compreender a importância que ele dava, não à guerra, mas à capacidade dos cidadãos de se levantarem para defender o país, e estarem decididos a sacrificar, in fine, a sua própria existência. É neste sacrifício que se pode calcular o valor real e o sucesso do ensino moral republicano. É o que explicou, em plena guerra, onde desta vez, o cidadão francês, educado de maneira leiga, não fracassou e onde o ensino moral republicano o levou à união sagrada:

Quando estes homens, que tudo os separava, educação, crenças, opiniões, interesses, foram jogados misturados na fornalha, diante do perigo supremo, todos obedeceram, instintivamente, a uma mesma ordem que cada um ouvia no fundo dele mesmo [...]. O judeu e o cristão, o padre e o livre pensador, o vendedor de jornais monárquicos, o sindicalista revolucionário não somente verteram o seu sangue juntos, eles juntos compartilharam no heroísmo, digamos, como eles, simplesmente no dever. (Buisson, 1916, p. 34)

Em tal perspectiva, Michèle Alten (2005) sublinha que se os Chants patriotiques de Déroulède foram amplamente divulgados nas escolas após o desastre de 1871, assistiuse breve a uma recrudescência da inspiração nacionalista que logo deu lugar a um humanismo republicano cuidadoso do progresso social e pacífico.

\section{Albert Dupaigne e as boas apropriações suíças}

Sob a Terceira República o influente Albert Dupaigne (1833-1910), antigo aluno da Escola Normal Superior, mais tarde, inspetor geral do ensino musical, foi o grande instigador da música nas escolas. Em 1878, quando das famosas conferências dadas aos professores delegados por ocasião da Exposição Universal, Dupaigne (1880, p. 284) deixou entrever as suas orientações referentes ao ensino musical. Ele considerava o canto como uma poderosa alavanca contra o materialismo e "um meio precioso de elevar o nível das almas às quais fala a língua musical". O inimigo designado era o caféconcerto, "a ruína da música [...] e uma instituição tão antimusical que antissocial". Vemos, na França republicana como na Europa das nações, a música escolar considerada com dupla função a de despertar as consciências patrióticas e a de servir de complemento à moral republicana. O conferencista deplorava também que "os artistas, os compositores e os editores só se preocupam com o mundo dos salões". Seguindo 
Alexandre Choron, revelava-se então urgente que "o bom gosto e a verdadeira instrução musical seja[m] levado[s] das classes favorecidas às classes populares" (1880, p. 302).

Quando ocorriam as conferências, Dupaigne apresentava uma série de coletâneas publicadas em francês aos professores presentes, entre as quais encontramos os Chants d'école à l'usage de la suisse française, de Kurz de Neuchâtel, publicados em dois volumes pela editora Sandoz et Fischbacher. A este respeito, Dupaigne comentou "que criticaram seguidamente diversos destes cantos pela sua origem alemã. Trata-se de um erro: grande parte deles é de origem suíça, o que é bem diferente. Naegeli, Schultz, Kurz e outros ilustres compositores, autores das músicas desses cantos, são suíços e não prussianos". Dupaigne concluiu, lembrando "que, em matéria de instrução primária, temos muito que aprender da Suíça. É um país amigo que não nos criticará se o imitarmos" (1880, p. 306).

Sem listar generalidades, vamos reter dois elementos do discurso de Dupaigne. Ele mostra, por um lado, uma diferenciação moral entre a Prússia e a Suíça alemã. O canto, considerado erroneamente prussiano, torna-se tolerável ao tomarem conhecimento da sua origem suíça, o que demonstra que este país desempenhou um papel potencial contornando a Alemanha em matéria pedagógica. Notaremos, por outro lado, que dos comentários de Dupaigne, se destaca de maneira implícita a ideia de uma Realpolitik das importações. Imitar as nações concorrentes comportava certos riscos ou desafios como o de deixar transparecer o seu atraso ou o de ser alvo de "críticas". Compreendemos então melhor o recurso às limpezas, que permitia, no momento de um processo de ressemantização, mais ou menos importante, acalmar ou apagar completamente a origem da importação.

Notamos nos fatos um pressuposto psicológico não negligenciável, que subentende certa desonra em imitar o vizinho, a se identificar com as suas produções. Porém, considerando-se pelo prisma da Kulturtransferforschung, este sentimento negativo desaparece, porque a incorporação é considerada não como uma cópia servil, mas como uma produção enriquecida de raízes e de filiações diversificadas (Espagne, 1999) que, na maioria dos casos, se torna, em um segundo tempo, autônoma e toma uma nova coloração. Esta orientação corresponde, aliás, à ideia que fazia Buisson da importação, que resulta, segundo ele, em uma "obra original", transpondo ad usum Galliae tudo o que a experiência estrangeira oferecia de melhor.

\section{O método Galin-Paris-Chevé (Rousseau)}

No dia 27 de julho de 1822, Jules Ferry inscrevia o canto como décima segunda matéria obrigatória da educação intelectual. Michèle Alten (2005, p. 9) explica que na ausência de tradição e de métodos, ele encarregou o legislador para organizar um programa completo. Os pedagogos optaram notadamente pelo método Galin-ParisChevé, especialmente criado para os iniciantes não músicos. Deve-se este sistema a Pierre Galin, de Bordeaux, (1786-1822), que na qualidade de autodidata teorizou a música como uma língua para apropriá-la ao maior número de pessoas sob uma forma cifrada. Apesar das diversas tentativas de divulgação em Bordeaux, depois em Paris, a sua obra não obteve o sucesso esperado. Foi o seu aluno e discípulo Aimé Paris (17981866) que salvou o método do esquecimento, para propagá-lo com a ajuda da sua irmã Nanine, esposa de Émile Chevé (1804-1864). 
Ora, é interessante constatar que este sistema foi objeto de uma intensa propaganda na Suíça romanda nos anos 1860. Alphonse Meylan (1834-1917) garantiu a passagem do método para a Suíça ocidental. Após ter estudado em Genebra, Meylan tornou-se gravador, depois professor de música no colégio de Genebra. Desde 1867, L'Éducateur lhe dá carta branca para popularizar o método cifrado, que Meylan utilizava há diversos anos, tendo em vista que o Conselho de Estado de Genebra o tinha adotado em 1861. Inicialmente céticos, mais tarde, convertidos pelo próprio Émile-Joseph-Maurice Chevé, os políticos de Genebra se mostraram satisfeitos com "os resultados obtidos em tão pouco tempo e isso sem cansaço para os mestres e sem trabalho ingrato e árido para as crianças" (Meylan, 1867, p. 40). Este movimento acelerou, aliás, a sua introdução nas escolas do cantão de Vaud no governo de Ruchonnet.

Novamente, na sua passagem de um contexto cultural a outro, o método sofreu uma transformação semântica. Meylan procurou ressuscitar a racionalidade do sistema musical pregada por Jean-Jacques Rousseau, que serviu de base ao sistema aperfeiçoado, em seguida, por Galin-Paris-Chevé, mas que tinha sido um tanto dissimulado pelos dois especialistas franceses. Em 1869, Meylan mostrou o seu projeto em um Cours de musique chiffrée et portée, adotado pelas direções da Instrução pública dos cantões de Vaud, Genève e Neuchâtel.

Finalmente, podemos racionalmente pensar que outros métodos musicais escolares circulavam no espaço franco-romando. Por meio da carta, abaixo, de Ferdinand Buisson a Friedrich Schneeberger ${ }^{24}$, tomamos conhecimento que este mestre de canto do Progymnase de Bienne desejava que o seu método fosse adotado na França:

Recebi honrosamente a sua carta datada de 10 de fevereiro corrente, e pela qual me manifesta o desejo de ver adotar e até mesmo tornar obrigatório na França um método de canto da sua autoria. Tenho certeza que o seu método contribui para facilitar o ensino do canto, mas devo lhe dizer que não cabe mais ao Ministro, conforme os regulamentos, recomendar ou aprovar os métodos destinados às Escolas. Para que possam ser adotados nos estabelecimentos escolares basta que eles não tenham sido objeto de nenhuma interdição. Só me resta lamentar que a minha intervenção não possa ser de nenhuma utilidade para a divulgação da sua obra ${ }^{25}$.

\section{De Appenzell a Paris, as colônias de férias}

Bem antes do desenvolvimento das colônias de férias, diversas instituições foram criadas com a finalidade de tratar as crianças raquíticas e escrofulosas ${ }^{26}$. Mas nenhuma destas instâncias conseguiu resultados tão bons em termos de higiene preventiva que as Ferien-Kolonien, criadas pelo pastor Hermann Walter Bion, da Turgóvia (1830-1909), descendente de uma família francesa vítima da revogação do Estado de Nantes. Bion dedicou a sua vida à assistência, na sua cidade, inicialmente, criando o hospital de

\footnotetext{
${ }^{24}$ Friedrich Schneeberger (1843-1906), professor de canto em Aarberg, assistiu às aulas do pai de todos os cantores da época, Gustav Weber. Em 1872, foi contratado no Progymnase de Bienne. Ele criou um método elementar de aprendizado de música, que tentou popularizar na França (Le Journal du Jura, 7 de junho de 2006, p. 4).

${ }^{25}$ Carta de F. Buisson a F. Schneeberger, Paris, 19 de fevereiro de 1880, AN, F17/12340.

${ }^{26}$ Pensamos principalmente nas caravanas escolares e nas viagens ziguezagueando em Töpffer ou nos albergues como o de Berck-sur-Mer. 
Trogen no cantão de Appenzell Rhodes-Extérieures, posteriormente fundando a casa das religiosas da Cruz-Vermelha em Zurich-Fluntern.

\section{O acompanhante Edmond Cottinet}

Na primavera de 1876, ele acompanhou alguns alunos com a saúde abalada nas montanhas de Appenzell e constatou que tiveram uma melhora rápida. Esta experiência concluinte deu início a um sucesso filantrópico mundial, propagado na Alemanha pelo dr. Warrentrapp, na Bélgica pelo dr. Kopps e, depois, em todo o continente e nos Estados Unidos através do pastor William Parsons (Rey-Herme, 1954).

Como comenta James Guillaume (1885, p. 308), na Revue Pédagogique, "a França esperou alguns anos antes de entrar, por sua vez, na via onde diversos países estrangeiros a tinham precedido". A declinação francesa foi o resultado do zelo de um punhado de indivíduos. Citaremos, de início, Edmond Cottinet (1824-1895), que foi o primeiro a tentar adotar a ideia do pastor Bion, que ele descobriu certamente na Revue Pédagogique de novembro de 1879. Nos meses seguintes, Cottinet foi à Suíça e a sua estada fez com que propagasse o conceito em Paris, nas suas escolas primárias do $9^{\circ}$ distrito. Globalmente, tratava-se de enviar, com a supervisão de professores e professoras, "os mais pobres entre os fracos, os mais merecedores entre os mais pobres" à Escola Normal de Chaumont, meninos, e à Escola Primária de Luxeuil, meninas, desocupadas durante as férias de verão. $O$ sucesso da operação permitiu a Cottinet de entrever uma aplicação a nível nacional.

De fato, assim que Ferdinand Buisson, convencido por Cottinet sobre o bem fundado das colônias para a juventude francesa, decidiu institucionalizar a experiência, a inteligência republicana utilizou $o$ argumento do atraso internacional para legitimar uma ação rápida: "A instituição se estendeu tão rapidamente em todos os países da Europa. Não podíamos ficar atrasados neste movimento", prega o normalista Francisque Sarcey na Revue Pédagogique de 1887. Por outro lado, faz-se necessário salientar o papel de Buisson que convocou, em 26 de maio de 1887, uma comissão encarregada da propagação e do incentivo das colônias de férias na França ${ }^{27}$. Philippe-Alexandre ReyHerme (1954, p. 239) sublinha que em apenas seis meses e graças ao ardor conjugado de Cottinet e Buisson, "as colônias de férias escolares tinham completado as suas infâncias experimentais para ingressar pela grande porta no campo das instituições reconhecidas". Utilizou-se também o argumento cívico, pois se tratava de fazer, "com as crianças cujo sangue e alma estavam viciados pela temporada nociva de Paris, soldados orgulhosos e bons patriotas" (Sarcey, 1887, p. 197).

\section{Uma ressemantização antinômica}

De um contexto original suíço ao contexto cultural francês, as colônias de férias geraram uma transformação semântica realmente singular. A escola republicana instrumentalizou o conceito para chegar a uma versão quase antagônica do esquema desenvolvido pelo pastor Bion. Esta atitude constitui, segundo nosso parecer, uma manifestação do que Houssaye (2010) resume com o termo desvio escolar. Ele explicita

${ }^{27}$ Buisson reúne personalidades de primeiro escalão. O Comitê Central dessa comissão foi presidido por Octave Gréard, vice-reitor da Academia de Paris e tinha como membros Mézières, da Academia Francesa e Carriot, diretor do ensino primário do Departamento da Seine. Edmond Cottinet, fundador das colônias de férias do $9^{\circ}$ distrito, foi escolhido como Secretário geral. 
que o projeto original de Bion tinha por objetivo tirar as crianças do ambiente escolar, lutando, assim, contra um excesso intelectualista da educação. Porém, na versão republicana, a função escolar vai se substituir à versão sanitária e social: "a pedagogia destas colônias fará surgir um verdadeiro desvio escolar, transformando, às vezes, os centros em gigantescas lições de coisas em um contexto regulamentar muito rigoroso" Houssaye (2010, p. 14). Aliás, em Paris, verificou-se logo o valor educativo das colônias:

O corpo não ganhou sozinho [...]. Estes pequenos parisienses, jamais tinham visto nada além do caminho que os levava da sua rua à escola; o horizonte dos seus pensamentos estava limitado a este espaço estreito. Imaginamos que a criança parisiense conhece Paris. Alguns, sem dúvida, vagaram por Paris. Isso em número bem reduzido. A maioria é, de certa maneira, servo da residência onde o seu pai mora, e fora da qual não é um lazer levá-los passear. Cottinet viu alguns que com doze anos, passando pelo Palais-Royal, perguntavam o que era, e ficavam encantados olhando o Louvre, sobre o qual jamais tinham ouvido falar. Por um motivo óbvio, não sabiam nada do interior. Eles estavam no ponto de uma ignorância absoluta e não teriam distinguido uma plantação de trigo de uma de aveia. (Sarcey, 1887, p. 197)

Houssaye (2010, p. 16) concluiu que finalmente era a criança que perdia com tudo isso, "ela [que] encontrar-se-á essencialmente limitada à sua modalidade escolar, à escola e às férias".

Constatamos que a questão central se cristalizava na escolha do tipo de colônia que era duplo: havia a possibilidade de enviar as crianças como pensionárias únicas em casas de famílias serranas, ou então em colônias estivais em escolas desocupadas e sob a responsabilidade de um mestre. Sabemos que esta questão chamou a atenção de especialistas europeus reunidos em uma conferência em Berlim em novembro de 1881. Schoost de Hamburgo e Reddersen de Brême eram claramente favoráveis ao sistema de colocação em casa de famílias "que dá mais liberdade à criança, ao passo que nas colônias ela se encontra constantemente sob a pressão da disciplina escolar" (Guillaume, 1885, p. 307). Se Cottinet pensava seguir, em primeiro lugar, o esquema de Bion, que ele tinha observado na Suíça, e colocar as crianças anêmicas em casas de camponeses serranos, ele se decidiu por um ajustamento para a França, optando pelo sistema coletivo:

Mas, entre o anúncio e a execução, uma pesquisa complementar revelou os riscos deste procedimento atraente. Colonos foram vistos, disseminados nas povoações do Jura, sem vigilância suficiente, impondo condições seguidamente muito precárias como hospedeiros, sem fornecimento adequado ou gananciosos... Preferiram, então, reunir os alunos em pequenos grupos, nas mãos de um mestre conhecido deles, procurando-Ihes como asilo alguma escola vazia durante as férias, onde a alimentação Ihes seria fornecida a preço fixado. (Rey-Herme, 1954, p. 212)

No primeiro congresso internacional sobre as colônias de férias de Zurique, em agosto de 1888, a delegação francesa, conduzida por Jules Steeg, decidiu radicalmente indicando que "de qualquer forma, os franceses pretendem permanecer fiéis à sua forma 
de colônia, que é a colônia coletiva" ${ }^{28}$. Às lógicas internas se misturavam, desde então, reivindicações nacionais. Por outro lado, por ocasião das comemorações, Steeg (1888, p. 221) "acrescentou: nada seria capaz de nos fazer esquecer quem somos, que não haveria nenhum mérito nestes encontros internacionais se não mantivéssemos zelosamente nosso sentimento nacional, e que mesmo com obstáculos permaneceríamos patriotas irredutíveis".

\section{Conclusão}

Por meio deste estudo de caso referente às transferências pedagógicas francoromandas, procurou-se demonstrar que a organização dos sistemas escolares europeus resulta de apropriações recíprocas, mais ou menos dissimuladas, e se constitui num resultado de um fenômeno eminentemente internacional. Estudar certas referências suíças da escola republicana francesa revela uma série de mediações apagadas, bem como uma quantidade de empreendimentos coletivos que se tornaram possíveis em virtude da criação de redes que favoreceram a importação massiva de métodos e de práticas pedagógicas elaboradas de maneira internacional.

A rede da proscrição francesa estabelecida na Suíça, após os eventos de 2 de dezembro de 1851, se mostra, por esta razão, significativa. Por outro lado, da sua trajetória helvética, o que reterão os irreconciliáveis, relegados fora de uma França que eles reformularão com a ajuda de um vocabulário inédito, trazido seguidamente de fora das fronteiras francesas? O que trarão da sua terra de proscrição se não as ferramentas para construir uma nova França, uma França desprovida de mundialização, uma França em parte feita de referências tomadas ao mesmo tempo entre Berlim e Moscou, entre Zurique e Genebra e cujo conteúdo a escola republicana reinterpretará para formular um romance a partir destes materiais intercambiáveis?

Seria demasiadamente pretensioso afirmar que a Terceira República encontra os seus fundamentos na Suíça, sobretudo quando conhecemos, a partir do estudo de Claude Digeon (1959), o peso da Alemanha no processo regenerativo francês. Todavia, Patrick Cabanel $(2003$, p. 22) tem razão ao lembrar que "a Terceira República nasceu também em torno do terraço de Veytaux". Não se poderia, no entanto, mostrar demasiadamente que foi também na Suíça romanda que se preparou, bem antes da chegada dos Republicanos nos assuntos externos, a reativação de uma pedagogia nacional liberal que desempenhou um papel determinante no processo criativo e unificador da nação francesa.

Assim, a ciência da educação alimentou-se de transferências culturais. O mesmo aconteceu com o continente sul-americano. Basta pensarmos nos trabalhos de Maria Helena Camara Bastos (2000), que demonstrou, de maneira pertinente, a recepção do pensamento de Buisson no Brasil pelos dos itinerários de Rui Barbosa (1849-1923) e de Joaquim José de Menezes Vieira (1848-1897).

Desde o fim da Idade Média - se pensarmos na elaboração da Ratio studiorum - as práticas e os métodos ultrapassam as fronteiras por meio de numerosos mediadores e se declinam em função de contextos locais específicos. Dito isto, um dos numerosos

${ }^{28}$ Esta delegação era composta pelo Sr. Jacoulet, diretor da Escola normal primária de Saint-Cloud, Pauline Kergomard, Inspetora geral das escolas maternais, d'Edmond Cottinet, Promotor das colônias de férias do $9^{\circ}$ distrito de Paris e do sr. Thomas, prefeito do $13^{\circ}$ distrito. 
desafios da pesquisa em História da Educação consiste em desconstruir os modelos escolares nacionais contemporâneos, a fim de reformular as filiações seguidamente ocultadas e as múltiplas referências estrangeiras que as alimentam.

\section{Referências}

ALTEN, Michèle. Musique scolaire et société dans la France de la Troisième république (2005). Tréma [en ligne], 25, mis en ligne le 6 janvier 2010, http://trema.revues.org/310.

ARNAUD, Pierre. Le militaire, l'écolier, le gymnaste: naissance de l'éducation physique en France (1869-1889). Lyon: Presses Universitaires de Lyon, 1991.

ARNAUD, Pierre (éds.). Les Athlètes de la républiques: gymnastique, sport et idéologie républicaine (1870-1914). Paris: L'Harmattan, 2000.

BARNI, Jules. Bulletin officiel du congrès de la paix et de la liberté de 1869. Lausanne: Association Typographique, 1869.

BARNI, Jules. Manuel républicain. Paris: Librairie Germer Baillière, 1872.

BASTOS, Maria Helena Camara. Ferdinand Buisson au Bresil: traces, signes, vestiges de ses idées pédagogiques. INRP: Service d'histoire de l'éducation, mai 2000. Journée d'étude sur Ferdinand Buisson. Disponible dans: <http://www.inrp.fr/she/buisson_ resumes.htm\#bresil>.

BASTOS, Maria Helena Camara. Ferdinand Buisson no Brasil: pistas, vestígios e sinais de suas idéias pedagógicas (1870-1900). Hist. Educ. [online], v. 4, n. 8, 2000, p. 79-109.

BENSOUSSAN, Georges; LAUGĖRE, Antoine. L'instruction civique: ses buts, ses agents, ses discours. Raison Présente, n. 74, 1985, p. 7-23.

BERT, Paul. L'instruction civique à l'école. Paris: Picard-Bernheim et Cie, 1882.

BORNET, Louis. Cours gradué d'instruction civique: manuel de l'école, de la famille et du citoyen. Fribourg: Imprimerie Ch. Marchand, 1856.

BOURZAC, Albert. Les bataillons scolaires 1880-1891: l'éducation militaire à l'école de la République. Paris: L'Harmattan, 2004.

BOVET, Pierre. Les origines fribourgeoises de l'enseignement moral et civique. Revue de Théologie et de Philosophie, 1932, p. 211-228.

BUISSON, Ferdinand. L'école et la nation en France. L'Année Pédagogique, 1913, p. 116.

BUISSON, Ferdinand. Souvenirs (1866-1916): conférence faite à l'Aula de l'Université de Neuchâtel le 10 janvier 1916. Paris: Fischbacher, 1916.

BUSSARD, Jean-Claude. L'éducation physique suisse en quête d'identité (1800-1930). Paris: L'Harmattan, 2007.

CABANEL, Patrick. Le dieu de la république: aux sources protestantes de la laïcité (18601900). Rennes: PUR, 2003.

CHANET, Jean-François. Vers l'armée nouvelle: république conservatrice et réforme militaires, 1871-1879. Rennes: Presses Universitaires de Rennes, 2006.

CHATELAIN, Charles. Considérations nouvelles sur le projet fédéral relatif à l'obligation du service militaire pour tout instituteur. L'Éducateur, n. 8, 1869, p. 113-118. 
CLARIS, Jean-Aristide. La proscription française en Suisse 1870-1871. Genève: Imprimerie Blanchard, 1872.

CZAKA, Véronique. Éduquer les corps et les âmes: histoire sociale et genrée de l'éducation physique en Suisse romande $\left(19^{\mathrm{e}}\right.$-début $20^{\mathrm{e}}$ siècle). Université de Lausanne, Faculté des Lettres, tese de doutorado em preparação.

DAGUET, Alexandre. Rapport sur l'École cantonale du 20 juillet 1857. Fribourg, 1857.

DEFRANCE, Jacques; JOSELEAU, Yves. Phokion Heinrich Clias (1782-1854). In: ARNAUD, P. Le militaire, l'écolier, le gymnaste: naissance de l'éducation physique en France (1869-1889). Lyon: Presses Universitaires de Lyon, 1991, p. 175-185.

DEFRANCE, Jacques. Phokion-Heinrich Clias (1782-1854): callisthénie ou somascétique naturelle appropriée à l'éducation physique des jeunes filles. In: VIGARELLO, Georges (éds.). Anthologie commentée des textes historiques de l'éducation physique et du sport. Revue EPS, 2001, p. 47-50.

DIGEON, Claude. La crise allemande de la pensée française (1870-1914). Paris: PUF, 1959.

DUPAIGNE, Albert. Conférence sur le chant dans les écoles (29 août 1878). Les Conférences pédagogiques faites aux instituteurs délégués à l'exposition universelle de 1878 [3 $3^{\text {ème }}$ édition]. Paris: Charles Delagrave, 1880.

ESPAGNE, Michel. Les transferts culturels franco-allemands. Paris: PUF, 1999.

FONTAINE, Alexandre. Transferts culturels et déclinaisons de la pédagogie européenne: le cas franco-romand au travers de l'itinéraire d'Alexandre Daguet (1816-1894). Universités de Fribourg-Paris VIII. Disponible dans: <http://unige.academia.edu/ AlexandreFontaine>.

GRATALOUP, Christian. Faut-il penser autrement l'histoire du monde? Paris: Armand Colin, 2011.

GUILLAUME, James. Les colonies de vacances et les écoles du IX $\mathrm{X}^{\mathrm{e}}$ arrondissement de Paris. Revue pédagogique, janvier-juin 1885, p. 305-315.

HOFSTETTER, Rita; DROUX, Joëlle (éds.). Les savoirs dans le champ éducatif: circulations, transformations, implémentations - pour une histoire sociale de la fabrique internationale des savoirs en éducation $\left(19^{\mathrm{e}}-20^{\mathrm{e}}\right.$ siècles), sous presse.

HOUSSAYE, Jean. Vouloir la coéducation, une fausse bonne idée? In: MAUBANT, Philippe; ROGER, Lucie (éds.). De nouvelles configurations éducatives: entre coéducation et communautés d'apprentissage. Québec: Presses de l'université du Québec, 2010, p. 13-21.

LALOI, Pierre (Ernest Lavisse). La première année d'instruction civique. Paris: Armand Colin \& Cie, 1882.

MASSY, Henriette. Notions de morale et d'éducation civique à l'usage des jeunes filles. Paris: Picard-Bernheim \& Cie, 1883.

MEYLAN, Albert. Musique populaire. L'Éducateur, n. 3, 1867, p. 39-41.

MEYLAN, Albert. Cours de musique chiffrée et portée: essai théorique, pratique et pédagogique des principes de l'école de J.-J. Rousseau-Galin-Paris-Chevé. Lausanne: Bridel, 1869.

MOMBERT, Monique. L'enseignement de l'allemand en France 1880-1918: entre modèle allemand et langue de l'ennemi. Strasbourg: Presses Universitaires de Strasbourg, 2001. 
MOREL-FATIO, Alfred. Don Francisco Amoros, marquis de Sotelo, fondateur de la gymnastique en France. Bulletin Hispanique, n. 27, 1925, p. 36-78.

MOUGNIOTTE, Alain. Les débuts de l'instruction civique en France. Lyon: Presses Universitaires de Lyon, 1991.

QUINET, Hermione. Mémoires d'exil - l'amnistie: Suisse orientale et bords du Léman. Paris: Armand le Chevalier, 1870.

QUINET, Edgar. Introduction au manuel du citoyen français. In: SCHMITT, G. J; BORNET, Louis. Essai d'instruction morale et civique à l'usage des familles et des écoles: manuel du citoyen français. Paris: A. Le Chevalier, 1872.

REY, Aristide. Les bataillons scolaires et la Révolution Française. Revue Pédagogique, juillet-décembre 1882.

REY-HERME, Philippe-Alexandre. Colonies de vacances: origines et premiers développements (1881-1906). Paris: Chez l'Auteur, 1954.

SARCEY, Francisque. Les colonies de vacances. Revue Pédagogique, janvier-juin 1887, p. 193.

SCHMITT, Georges Joseph; BORNET, Louis. Essai d'instruction morale et civique à l'usage des familles et des écoles: manuel du citoyen français avec une introduction d'Edgar Quinet. Paris: A. Le Chevalier, 1872.

SPIVAK, Marcel. Colonel François Amoros y Ondeano (1770-1848): manuel d'éducation physique, gymnastique et morale. In: VIGARELLO, Georges (éds.). Anthologie commentée des textes historiques de l'éducation physique et du sport. Paris: Revue EPS, 2001, p. 13-17.

STEEG, Jules. Congrès international de Zurich (colonies de vacances et hygiène scolaire. La Revue Pédagogique, juillet-décembre 1888, p. 211-222.

THIESSE, Anne-Marie. La création des identités nationales: Europe $18^{\mathrm{e}}-19^{\mathrm{e}}$ siècle. Paris: Seuil, 1999.

VUILLEUMIER, Marc. Georges Joseph Schmitt: le confédéré de Fribourg et les Républicains français. Documents inédits. Revue Suisse d'Histoire, n. 24, 1974, p. 66-97.

WEBER, Eugen. Gymnastique et sport en France à la fin $\mathrm{du} 19^{\mathrm{e}}$ siècle: opium des classes? Recherches, n. 43, 1980, p. 185-220.

WERNER, Michael. Transferts culturels: le dictionnaire des sciences humaines. Paris: PUF, 2006.

ALEXANDRE FONTAINE é pesquisador na Universidade de Genebra, PhD pela Universidade de Friburgo (Suíça) e Paris VIII.

Endereço: University of Geneva, Uni-Mail, office 4333, 40 bd. du Pont-d'Arve, $\mathrm{CH}$ 1205 Geneva.

E-mail: alexandre.fontaine@unige.ch.

Recebido em 11 de agosto de 2013.

Aceito em 31 de outubro de 2013. 